\title{
ENDOPHYTE-INFECTED MEADOW FESCUE AND LOLINE ALKALOIDS AFFECT ARGENTINE STEM WEEVIL LARVAE
}

\author{
A.J. POPAY ${ }^{1}$, B.A. TAPPER ${ }^{2}$ and C. PODMORE ${ }^{1}$ \\ ${ }^{1}$ AgResearch, Ruakura Research Centre, Private Bag 3123, Hamilton, \\ New Zealand \\ ${ }^{2}$ AgResearch, Grasslands, Private Bag 11008, Palmerston North, New Zealand \\ Corresponding author: alison.popay@agresearch.co.nz
}

\begin{abstract}
In a meadow fescue plant assay, a lower percentage of tillers on endophyte-infected $(\mathrm{E}+)$ than endophyte-free $(\mathrm{E}-)$ plants on which eggs had been laid were damaged by Argentine stem weevil (ASW) larvae. There were indications of endophyte-mediated toxicity to young larvae. The percentage of damaged tillers on $\mathrm{E}-$ and $\mathrm{E}+$ plants without ASW eggs was similar when they were planted alongside a plant with eggs, but severity of damage was less on E+ plants. In an artificial diet experiment, eggs took 2-3 days longer to hatch on an alkaloid-free diet than on diets containing either of two loline alkaloids produced by E+ meadow fescue. Growth and development of larvae was reduced by up to $36 \%$ at two higher concentrations of $N$-formyl loline (NFL) relative to the lowest concentration, and to a lesser extent by $N$-acetyl norloline. Larval survival declined with increasing concentrations of both alkaloids, with the highest mortality occurring at the two higher concentrations of NFL. Keywords: $N$-formyl loline, $N$-acetyl norloline, Listronotus bonariensis, Neotyphodium uncinatum, Lolium pratense.
\end{abstract}

\section{INTRODUCTION}

The fungal endophytes Neotyphodium coenophialum in tall fescue (Lolium arundinaceum syn. Festuca arundinacea) and N. uncinatum in meadow fescue (Lolium pratense syn. Festuca pratensis), produce saturated pyrrolizidine alkaloids known as lolines. Of several loline derivatives that occur in these plants, $N$-formyl loline (NFL), $\mathrm{N}$-acetyl norloline (NANL) and $\mathrm{N}$-acetyl loline (NAL) are the major components (Bush et al. 1993; Justus et al. 1997). Tall fescue infected with strains of $N$. coenophialum produce some or all of these loline isomers as well as low levels of peramine. These endophytes provide their hosts with protection against major New Zealand grass pests, such as root aphid (Aploneura lentisci) (Jensen \& Popay 2007), pasture mealybug (Balanococcus poae) (Pennell \& Ball 1999), Argentine stem weevil (ASW) (Listronotus bonariensis) and black beetle (Heteronychus arator) (Popay et al. 2005). Lolines are the only alkaloids produced in meadow fescue infected with its natural endophyte $N$. uncinatum. This plant/endophyte combination reduces ASW adult feeding (Patchett et al. 2008a) and ASW oviposition (Jensen et al. 2009), A. lentisci populations (Schmidt \& Guy 1997), and feeding and growth of grass grub (Costelytra zealandica) larvae (Popay et al. 2003; Patchett et al. 2008b). The loline alkaloids themselves are known to affect ASW adults (Jensen et al. 2009), bird cherry oat aphids (Rhopalosiphum padi) (Wilkinson et al. 2000), grass grub and porina (Wiseana cervinata) larvae (Popay \& Lane 2000) as well as a range of other insects (Yates et al. 1989; Patterson et al. 1991; Riedell et al. 1991; Dahlman et al. 1997; Dougherty et al. 1999).

The loline alkaloids have no known effect on grazing mammals (Schardl et al. 2007). This, together with the broad spectrum insecticidal activity of these secondary 
metabolites, makes them potentially a very important resource for the exploitation of fungal endophytes for control of insect pests in grasses. This paper reports the effect on ASW larvae of $N$. uncinatum in meadow fescue plants and of two loline isomers produced by this endophyte.

\section{Meadow fescue plant experiment}

\section{METHODS}

Two seed lines (1 and 2) of meadow fescue both infected with $N$. uncinatum and a third endophyte-free seed line were grown from seed and exposed to ASW adult feeding and oviposition as described in Jensen et al. (2009). Endophyte status of the plants was confirmed by tissue print immunoblotting prior to the experiment. The experiment was carried out in a controlled environment room at $20^{\circ} \mathrm{C}$ in $16: 8 \mathrm{~h}$ light:dark. Two days after oviposition by the weevil adults was recorded, the experiment described by Jensen et al. (2009) was rearranged to test if $N$. uncinatum infection was active against larvae. Of the 10 replicate plants of each of the three seed lines, eggs had been found on five endophyte-infected (E+) (two plants from seed line 1 and three from seed line 2 ) and five endophyte-free (E-) plants but considerably fewer eggs were found on the $\mathrm{E}+$ plants. In order to expose the infected plants to larvae and enable comparisons to be made of the damage to these and to E-plants, an endophyte-infected plant and an endophyte-free plant, both without eggs, were planted alongside a plant with eggs. Of the plants with eggs that were grouped with plants without eggs, four were $\mathrm{E}-(\mathrm{n}=45,29,18$ and 12 eggs/plant) and one was an E+ plant ( $\mathrm{n}=11 \mathrm{eggs} / \mathrm{plant})$. Each of the plants harbouring eggs was transplanted into the centre of a $15 \mathrm{~cm}$ diameter pot with an E-and an E+ plant without eggs transplanted on either side. These five pots were returned to the controlled environment room, along with the remaining five single plants on which eggs had been recorded (one E- plant with 3 eggs and four E+ plants with 11, 2, 2 and $1 \mathrm{egg} / \mathrm{plant}$ ) and $10 \mathrm{E}+$ plants on which no eggs had been found. No larval damage was subsequently found on the latter 10 plants and these were not included in any analyses. The single plants remained in the original $9 \mathrm{~cm}$ diameter pots as described in Jensen et al. (2009). All plants were 3 months old, with between 8 and 20 tillers per plant.

Three weeks later on 21 June 2006, each tiller on each plant was checked for larval damage and the presence of larvae. The severity of damage was scored on a scale of 1-3 where 1 = minor surface damage to the tiller, without severance of the central leaf; $2=$ penetration of the tiller by the larvae and moderate mining; $3=$ tiller destroyed by larval mining. The percentage of tillers damaged by larvae and the proportion of damaged tillers with minor, moderate or severe damage was compared by ANOVA and means were separated using Tukey's HSD test.

\section{Loline bioassay}

In October 2008, field-collected ASW adults were caged onto seed trays of endophytefree ryegrass (Lolium multiflorum) cv. Moata for 2-3 weeks during which time the grass was inspected regularly for the presence of eggs. Egg collections were made over a period of time between 5 and 19 November to obtain sufficient eggs to carry out the trial. Eggs were stored on damp filter paper in Petri dishes at $4^{\circ} \mathrm{C}$ until required for the trial.

NFL was prepared from meadow fescue seed infected with $N$. uncinatum while NANL was obtained from tall fescue seed infected with endophyte AR542, which yields only the norloline derivatives (Ball \& Tapper 1999). Coarsely milled seed was serially extracted using methanol, acidified and concentrated before partitioning and further extraction using chloroform. The chloroform extractions were concentrated and purified and then further isolated by vacuum distillation. Mass spectrometry showed the NFL contained minor quantities of NAL and confirmed the identity of NANL.

Solutions of NFL (90\% pure) and NANL (95\% pure) in water were received at Ruakura on 28 November 2008. An artificial diet for ASW larvae (Malone \& Wigley 1990) was prepared and appropriate amounts of each solution were added to $20 \mathrm{~g}$ of diet to give wet weight concentrations of (1) 400, (2) 800 and (3) $1600 \mu \mathrm{g} / \mathrm{g}$ of diet for either NFL or NANL. For the two lower concentrations of NFL and NANL, water was also added 
so that each diet treatment received the same amount of additional liquid $(2.9 \mathrm{ml})$. A control diet was prepared containing $2.9 \mathrm{ml}$ of water only.

For each treatment, a plug of diet $(6 \mathrm{~mm}$ diameter $\times$ approx. $8 \mathrm{~mm})$ was added to each of 30 replicate $2 \mathrm{ml}$ microcentrifuge vials. A single ASW egg was then placed onto each diet plug ensuring that each treatment had the same number of eggs from each collection time. Half of the eggs used in each treatment were collected 10-12 days prior to the trial being set up, a further 12 eggs had been collected 15-16 days before and the remaining three eggs in each treatment had been collected 23 days before the trial commenced. Although eggs were collected on 6 days over a 14 day period, those collected on consecutive days were treated as a single collection time. The two main collection times were subsequently used as a factor in the analysis.

The vials were checked at 16x magnification on days 3, 6, 10,14 and 19 and thereafter at weekly intervals for 11 weeks. Egg hatching was monitored up to day 19 and the following week any eggs that had not hatched were dissected to determine their stage of development. Larval survival was monitored and their position in relation to the diet (on the diet, close to the diet or elsewhere in the vial) recorded as a measure of deterrence of the treatments. Data are presented starting from 10 days after eggs were placed on the diets when most of the larvae had hatched. The width of the head capsule and length of the body (including the head) were measured in Week 5 and thereafter the instar of each surviving larva was determined each week by the size of the head capsule.

After reaching maturity, fourth instar larvae were transferred along with their diet into clean vials two-thirds filled with compacted sterile vermiculite moistened with water to enable them to pupate. Observations of their position and tunnelling into the vermiculite were made over the following 3 weeks.

Data for time to egg hatching, head capsule and body length measurements were analysed by an analysis of variance after log transformation. Data are presented as the arithmetic means with a back transformed SED. The position of larvae, the proportion in different instars and survival were analysed using a generalised linear model with a binomial distribution and logit link function.

\section{Meadow fescue plant experiment}

\section{RESULTS}

A lower percentage of tillers were damaged by ASW larvae on the E+ than on Eplants on which eggs had been laid when the five plants of each were compared (Table 1). Of the tillers damaged by larvae, $88 \%$ of tillers on E- plants were recorded as having severe damage compared with only $10 \%$ severely damaged on $\mathrm{E}+$ plants $(\mathrm{P}<0.001)$. The majority of damaged tillers on E+ plants had only minor damage $(66 \%)$. Five live mature larvae were found in damaged E- tillers whereas of five larvae found on E+ plants, four had died as first or second instars and only one had survived to maturity.

Where plants with eggs were grouped with plants without eggs, the plants with eggs had a significantly higher percentage of damaged tillers compared with the plants without eggs (Table 1). For the plants without eggs, the percentage of tillers on E+ and $\mathrm{E}-$ plants that were damaged by larvae was similar. More larvae were found on the E+ plants $(\mathrm{n}=14$ live +1 dead) compared with the $\mathrm{E}$ - plants ( $\mathrm{n}=6$ live) and all were third or fourth instars. Of the tillers damaged by larvae, more than $60 \%$ of those on plants with eggs and on the E- plants without eggs were severely damaged and less than $13 \%$ had moderate damage, whereas for the E+ plants without eggs $39 \%$ had severe damage but $40 \%$ had moderate damage (Table 1).

\section{Loline bioassay}

Eggs placed on the water-only control diets took significantly longer to hatch than those on the diets containing the loline alkaloids (average days to hatch: Control 8.3, NANL 5.3, NFL 6.1; Ave SED 1.15; $\mathrm{P}=0.006$ ). Egg incubation times were similar at all concentrations of NFL and NANL (data not presented) and were not affected by egg collection time. The final percentage of eggs that hatched was $93 \%$ in each treatment except for NANL2 in which $90 \%$ of eggs hatched. 
TABLE 1: Mean number of tillers per plant and the percentage of tillers damaged by Argentine stem weevil larvae on meadow fescue plants with $(\mathrm{E}+)$ and without $(\mathrm{E}-)$ infection by $N$. uncinatum. Also shown is the percentage of damaged tillers having minor, moderate or severe damage.

\begin{tabular}{lccccc}
\hline & & & \multicolumn{3}{c}{$\%$ of damaged tillers with } \\
\cline { 4 - 6 } & $\begin{array}{c}\text { No. of } \\
\text { tillers/plant }\end{array}$ & $\begin{array}{c}\text { \% Tillers } \\
\text { damaged }\end{array}$ & $\begin{array}{c}\text { Minor } \\
\text { damage }\end{array}$ & $\begin{array}{c}\text { Moderate } \\
\text { damage }\end{array}$ & $\begin{array}{c}\text { Severe } \\
\text { damage }\end{array}$ \\
\hline All plants with eggs & & & & & \\
E- (n=5) & 10 & 82 & 3 & 9 & 88 \\
E+ (n=5) & 14 & 26 & 66 & 24 & 10 \\
LSD (P=0.05) & & 28 & 28 & - & 20 \\
Significance & & $\mathrm{P}<0.05$ & $\mathrm{P}<0.001$ & $\mathrm{~ns}$ & $\mathrm{P}<0.001$ \\
Grouped plants & & & & & \\
Plants with eggs ${ }^{2}$ & 12 & 89 & 18 & 13 & 69 \\
E- No eggs (n=5) & 9 & 45 & 7 & 10 & 63 \\
E+ No eggs (n=5) & 17 & 38 & 22 & 40 & 39 \\
LSD (P=0.05) & & 29 & - & 29 & 24 \\
Significance & & $\mathrm{P}<0.01$ & $\mathrm{~ns}$ & $\mathrm{P}=0.06$ & $\mathrm{P}<0.05$ \\
\hline
\end{tabular}

${ }^{1}$ Combined data from both seed lines.

${ }^{2}$ Four E-plants and $1 \mathrm{E}+$ plant.

The percentage of larvae found on the diets, close to the diets (within $4 \mathrm{~mm}$ ) or higher up in the vial was affected by significant interactions between concentration of alkaloids and egg collection times. In Weeks 2 and 3, on diets without alkaloids or at the lowest concentrations of alkaloids, more larvae from Collection 2 were found on the diet compared with those from Collection 3 (65\% cf. 34\%), whereas the reverse was true for those larvae on the vial wall $(21 \%$ from Collection 2 on the vial walls cf. $45 \%$ from Collection 3). As the concentration of alkaloids increased, fewer larvae from Collection 2 and more from Collection 3 were found on the diets (e.g. at the highest concentration, $33 \%$ of Collection 2 larvae were on the diet cf. $46 \%$ of Collection 3 ). In Week 4 for larvae on the control diets, $71 \%$ from Collection 2 were found on the vial wall, compared with none of the larvae from Collection $3(\mathrm{P}=0.007)$. The majority of larvae $(60 \%)$ from Collection 3 were recorded on the diet at this time. In Week 6, however, there were indications of an alkaloid effect with significantly more larvae in the NFL treatments on the inside of the vial away from the diet plug compared with those in the NANL treatment (29\% cf. 15\%; $\mathrm{P}=0.041)$. Taking all recordings of position together from Week 2 to Week 6, larvae were recorded on the different diets between 52 and $64 \%$ of the time with no indications of an alkaloid treatment effect.

The loline alkaloids affected growth and development of larvae with significant alkaloid by concentration interactions. Average head capsule width and body length measured in Week 6 (Fig. 1) were significantly higher for larvae on NFL1 $(400 \mu \mathrm{g} / \mathrm{g})$ than for those on NFL2 $(800 \mu \mathrm{g} / \mathrm{g})$ and NFL3 $(1600 \mu \mathrm{g} / \mathrm{g})$ (alkaloid*concentration interaction: $\mathrm{P}=0.003$ and $\mathrm{P}=0.006$ respectively for head capsule and body length measurements). Although larvae on the NFL2 and NFL3 were smaller than larvae on all other treatments, their size did not differ significantly from those on the control or the NANL treatments (Fig. 1).

The percentage of larvae still in the first instar at Week 6 was also greater on the NFL2 and NFL3 diets than on the NFL1 diet ( $\mathrm{P}=0.004)$ (Table 2) with no differences between the other treatments. Conversely there were fewer larvae in the NFL2 treatment in particular, but also in NFL3 and NANL3, that had reached the third and fourth instar compared with NFL1 (alkaloid*concentration interaction: $\mathrm{P}=0.032$ ). By Week 9, a significant effect of alkaloid concentration $(\mathrm{P}=0.019)$ was apparent with the intermediate concentrations of NFL and NANL having the highest percentage of live first instars relative to the other concentrations. 

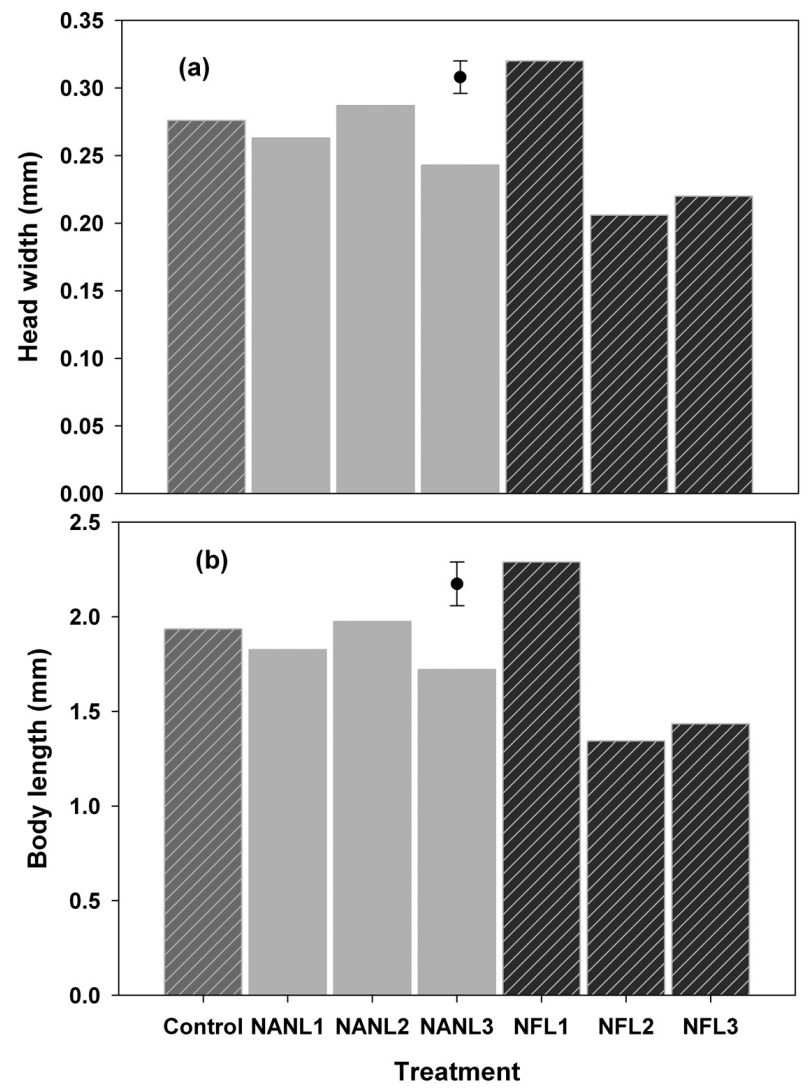

FIGURE 1: Head capsule width $(\mathrm{mm})$ and body length $(\mathrm{mm})$ of Argentine stem weevil larvae 6 weeks after eggs were placed on diets containing either $N$-acetyl norloline (NANL) or $N$-formyl loline (NFL) at three concentrations $(1=400,2=800,3=1600 \mu \mathrm{g} / \mathrm{g})$ or a control diet without alkaloids. Error bar represents the SED.

The lower percentage of first instars in the NFL3 and NANL3 was due to a high mortality of these larvae prior to Week 9, rather than due to development of the larvae. Development of larvae on NFL1 appeared to be faster than for other treatments with $17 \%$ of larvae in the fourth instar by Week 6 and $69 \%$ by Week 9 , although differences between treatments were not significant. At Week $11,60 \%$ and $36 \%$ of larvae in the NANL1 and NANL2 treatments were still in the third instar compared with $11 \%$ in the control. Several of these larvae failed to develop beyond the third instar.

Larval survival was lowest on the NFL2 and NFL3 treatments and greatest on the NFL1 with the control and NANL treatments intermediate between these (Fig. 2). The majority of larvae died as first instars with most of the mortality occurring between Weeks 5 and 7. At Week 4, a significant alkaloid by concentration interaction $(\mathrm{P}=0.01)$ occurred in which survival of larvae in NFL3 was significantly lower than in the other NFL treatments whereas there was no significant difference in the NANL treatments. During Weeks 5-11, survival decreased significantly with increasing concentrations of NFL and NANL $(\mathrm{P}<0.05)$. Larval survival on the control diet was similar to that on the 
lowest concentration of the alkaloids and survival at the middle and high concentrations of the alkaloids was also similar. Despite a two-fold difference in survival between the NFL3 and NANL3 treatments by Week 11, this difference was also not significant.

None of the fourth instar larvae transferred into vermiculite had pupated after 3 weeks. Subsequently, six of eight larvae in the control treatment and four of 11 in the NFL1 treatment formed tunnels in the vermiculite, compared with only three of 19 larvae in all the NANL treatments.

TABLE 2: Percentage of live Argentine stem weevil larvae in different instar stages in Week 6 and Week 9 after exposure to diets containing either $N$-acetyl norloline (NANL) or $N$-formyl loline (NFL) at three concentrations $(1=400,2=800,3=1600 \mu \mathrm{g} / \mathrm{g})$ or a control diet without alkaloids.

\begin{tabular}{|c|c|c|c|c|c|c|c|}
\hline Instar & Control & NANL1 & NANL2 & NANL3 & NFL1 & NFL2 & NFL3 \\
\hline \multicolumn{8}{|c|}{ Week 6} \\
\hline $1^{\text {st }}$ & 45 & 57 & 42 & 58 & 33 & 83 & 83 \\
\hline $2^{\text {nd }}$ & 30 & 17 & 21 & 26 & 29 & 13 & 0 \\
\hline $3^{\text {rd }}$ & 25 & 22 & 37 & 16 & 21 & 4 & 17 \\
\hline $4^{\text {th }}$ & 0 & 4 & 0 & 0 & 17 & 0 & 0 \\
\hline $\mathrm{n}$ & 20 & 23 & 19 & 19 & 24 & 23 & 18 \\
\hline \multicolumn{8}{|c|}{ Week 9} \\
\hline $1^{\text {st }}$ & 17 & 18 & 21 & 10 & 6 & 56 & 17 \\
\hline $2^{\text {nd }}$ & 17 & 0 & 7 & 20 & 13 & 0 & 17 \\
\hline $3^{\text {rd }}$ & 17 & 55 & 43 & 30 & 13 & 22 & 33 \\
\hline $4^{\text {th }}$ & 50 & 27 & 29 & 40 & 69 & 22 & 33 \\
\hline $\mathrm{n}$ & 12 & 11 & 14 & 10 & 16 & 9 & 6 \\
\hline
\end{tabular}

\section{DISCUSSION}

Infection of meadow fescue with the endophyte $N$. uncinatum reduced the number of tillers damaged by ASW larvae primarily as a result of a marked reduction in oviposition that occurred on these plants (Jensen et al. 2009). The presence of dead larvae, observed only on endophyte-infected plants on which eggs were laid, suggests also that there is endophyte-mediated toxicity to young larvae. Similarly, the reduced severity of damage to those tillers attacked by ASW larvae indicates that the endophyte is reducing ASW larval feeding either by deterrence or by toxicity. However, larvae appeared to transfer equally into $\mathrm{E}+$ and $\mathrm{E}$ - plants that were exposed to larval infestations from neighbouring plants harbouring high egg numbers, subsequently causing similar amounts of damage. The relatively high numbers of larvae found in the E+ plants together with a lower damage severity score relative to the E-plants may indicate that larvae transferred later into these plants than into the E- plants. Alternatively the fewer larvae found on the $\mathrm{E}$ - plants relative to E+ may be a result of earlier maturing of these larvae, which have then left the plants to pupate.

The bioassay of the two loline derivatives was complicated by the collection of eggs at different times and their subsequent storage prior to the trial being set up, which is likely to have affected the development and survival of the larvae. Other studies have shown ASW larval development through to maturity, on the same artificial diet used in this experiment, occurs within 4-6 weeks with a relatively low mortality (Prestidge \& Gallagher 1985; Dymock et al. 1989; Popay et al. 1990). The interactions between egg collection times and position of the larvae provide evidence of unexpected effects of egg storage on subsequent larval behaviour and may have masked any deterrent effects of the alkaloids. 


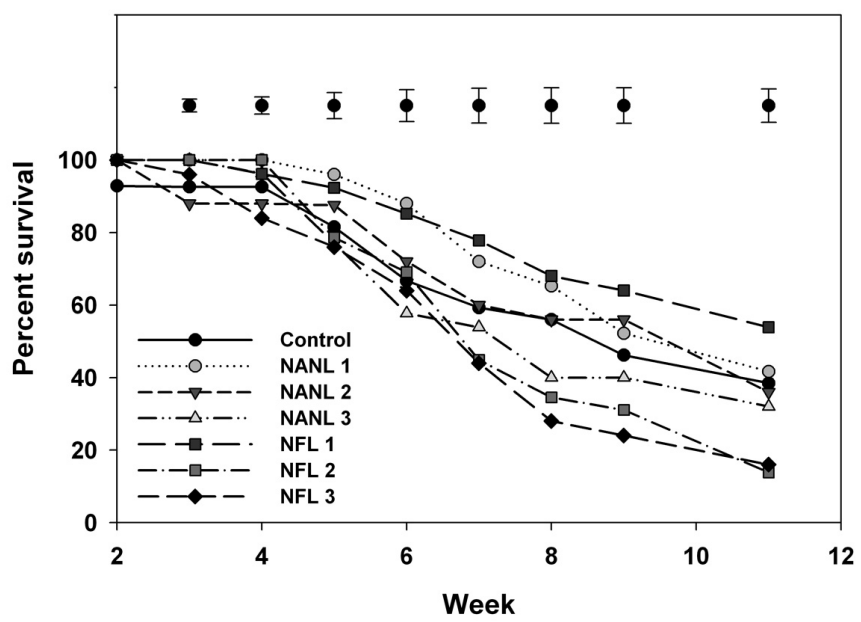

FIGURE 2: Percent survival of Argentine stem weevil larvae exposed to diets containing either $N$-acetyl norloline (NANL) or $N$-formyl loline (NFL) at three concentrations $(1=400,2=800,3=1600 \mu \mathrm{g} / \mathrm{g})$ or a control diet without alkaloids. Error bars represent the SED.

Despite the slow development and poor survival in the control, the bioassay has provided evidence that NFL at high concentrations is toxic to ASW larvae, reducing their growth, development and survival. Even at the high concentrations of NFL, however, a few larvae were able to survive and progress their development through to the fourth instar. This reflects the results shown on the meadow fescue plants where mature larvae were found in E+ plants. Larval age has been shown to be a factor in the sensitivity of some insects to endophyte (e.g. Hardy et al. 1986). In contrast to the NFL results, NANL had only minor effects on growth and development of ASW larvae but affected larval survival as evidenced by the significant increase in mortality with increasing concentrations of both loline derivatives. The relatively high proportion of larvae in the NANL1 and NANL2 treatments that were still in the third instar at Week 11 and the failure of most of the fourth instars to tunnel into the vermiculite, is also indicative of some subtle toxic effects of this alkaloid on ASW larvae. Tall fescue infected with the endophyte AR542 (Max PTM) produces only the NANL derivative and no NFL or NAL, as well as low levels of peramine. This plant/endophyte combination reduces ASW larval damage in the field (Popay et al. 2005) but the relative roles of NANL and peramine in these effects on ASW are unknown.

Two surprising results in the loline bioassay warrant further investigation. The first was the influence that the alkaloids had at all concentrations in decreasing the time taken for the eggs to hatch compared with the water only control diet. The loline alkaloids are nitrogenous compounds and it is possible that absorption of nutritive substances increased the rate of embryonic development. There is little information in the literature on plant factors that may affect egg incubation times. The second interesting result was the markedly better performance of larvae on the NFL1 diet compared with those on the two higher concentrations. Furthermore, although differences were not significant, those larvae on the NFL1 diet also had the highest rate of growth, development and survival compared with the control and NANL treatments. Further testing would be useful to confirm this result, particularly as it has been shown that insects occasionally do better on tall fescue hosting $N$. coenophialum than on endophyte-free tall fescue (e.g. Bultman \& 
Bell 2003; Ball et al. 2006). The $400 \mu \mathrm{g} / \mathrm{g}$ of NFL in this diet is estimated to be equivalent to $2000 \mu \mathrm{g} / \mathrm{g}$ dry weight of material, a concentration that is within the reported range of NFL concentrations in the pseudostems of meadow fescue plants infected with $N$. uncinatum (Justus et al. 1997) and in tall fescue infected with $N$. coenophialum (Bush et al. 1993). The equivalent dry weight concentration for the NFL3 and NANL3 treatments is estimated to be about $8000 \mu \mathrm{g} / \mathrm{g}$ and this is within the range for NFL measured in infected meadow fescue plants (A.J. Popay, unpubl. data) although it is higher than that measured by Justus et al. (1997). The lack of difference between the two higher concentrations of NFL suggests that a threshold concentration for the effect of this alkaloid on ASW larvae lies between the 400 and $800 \mu \mathrm{g} / \mathrm{g}$ wet weight. This is considerably higher than the $400 \mu \mathrm{g} / \mathrm{g}$ dry weight estimated by Patchett et al. (2008a) to be deterrent to adult ASW in planta but lower than the equivalent dry weight concentrations that appeared to affect adults in artificial diet experiments (Jensen et al. 2009).

Utilising endophytes for biological control of insect pests in grasses is important for development of productive and persistent pastures in agriculture. Understanding the role of different alkaloids in protecting plants against various insects is an important aspect of using these endophytes. The effects of the loline alkaloids in reducing growth, development and survival of ASW larvae, together with their effects on adult weevils (Jensen et al. 2009), adds to growing evidence of their broad spectrum insecticidal activity and potential importance for control of insect pests.

\section{ACKNOWLEDGEMENTS}

The authors thank Neil Cox for statistical analysis. This study was funded by PGGWrightsons, Grasslanz Technology Ltd and the New Zealand Foundation for Research, Science and Technology Contract C10X0815: Exploiting Opportunities from Forage Plant Genomics.

\section{REFERENCES}

Ball OJ-P, Tapper BA 1999. The production of loline alkaloids in artificial and natural grass /endophyte associations. Proceedings of the $52^{\text {nd }}$ New Zealand Plant Protection Conference: 264-269.

Ball OJ-P, Coudron TA, Tapper BA, Davies E, Trently D, Bush LP, Gwinn KD, Popay AJ 2006. Importance of host plant species, Neotyphodium endophyte isolate, and alkaloids on feeding by Spodoptera frugiperda (Lepidoptera : Noctuidae) larvae. Journal of Economic Entomology 99: 1462-1473.

Bush LP, Fannin FF, Siegel MR, Dahlman DL, Burton HR 1993. Chemistry, occurrence and biological effects of saturated pyrrolizidine alkaloids associated with endophytegrass interactions. Agriculture, Ecosystems and Environment 44: 81-102.

Bultman TL, Bell GD 2003. Interaction between fungal endophytes and environmental stressors influences plant resistance to insects. Oikos 103: 182-190.

Dahlman DL, Siegel MR, Bush LP 1997. Insecticidal activity of N-formylloline. Constraints on Forage and Grassland Production. XVIII International Grasslands Congress, Canada. Pp 13-15.

Dougherty CT, Knapp FW, Bush LP 1999. Mortality of horn fly larvae (Diptera: Muscidae) in bovine dung supplemented with ergotamine and $N$-formyl loline. Journal of Medical Entomology 36: 73-77.

Dymock JJ, Prestidge RA, Rowan DD 1989. The effects of lolitrem B on Argentine stem weevil larvae. Proceedings of the $42^{\text {nd }}$ New Zealand Weed and Pest Control Conference: $73-75$.

Hardy TN, Clay K, Hammond AMJ 1986. Leaf age and related factors affecting endophyte-mediated resistance to fall armyworm (Lepidoptera: Noctuidae) in tall fescue. Environmental Entomology 15: 1083-1089.

Jensen JG, Popay AJ 2007. Reductions in root aphid populations by non-toxic endophyte strains in tall fescue. Proceedings of the $6^{\text {th }}$ International Symposium on Fungal Endophytes of Grasses. Grassland Research and Practice Series No. 13. Pp. 341344. 
Jensen JG, Popay AJ, Tapper BA 2009. Argentine stem weevil adults are affected by meadow fescue endophyte and its loline alkaloids. New Zealand Plant Protection 62: $12-18$.

Justus M, Witte L, Hartmann T 1997. Levels and tissue distribution of loline alkaloids in endophyte-infected Festuca pratensis. Phytochemistry 44: 51-57.

Malone LA, Wigley PJ 1990. A practical method for rearing Argentine stem weevil, Listronotus bonariensis (Coleoptera: Curculionidae) in the laboratory. New Zealand Entomologist 13: 87-89.

Patchett BJ, Chapman RB, Fletcher LR, Gooneratne SR 2008a. Endophyte-infected Festuca pratensis containing loline alkaloids deters feeding by Listronotus bonariensis. New Zealand Plant Protection 61: 205-209.

Patchett BJ, Chapman RB, Fletcher LR, Gooneratne SR 2008b. Root loline concentration in endophyte-infected meadow fescue (Festuca pratensis) is increased by grass grub (Costelytra zealandica) attack. New Zealand Plant Protection 61: 210-214.

Patterson CG, Potter DA, Fannin FF 1991. Feeding deterrency of alkaloids from endophyte-infected grasses to Japanese beetle larvae. Entomologia Experimentalis et Applicata 61: 285-289.

Pennell C, Ball OJ-P 1999. The effects of Neotyphodium endophytes in tall fescue on pasture mealy bug (Balanococcus poae). Proceedings of the $52^{\text {nd }}$ New Zealand Plant Protection Conference: 259-263.

Popay AJ, Lane GA 2000. The effect of crude extracts containing loline alkaloids on two New Zealand insect pests. Proceedings of the 4th International Neotyphodium/ Grass Interactions Symposium. Soest, Germany. Pp. 471-475.

Popay AJ, Prestidge RA, Rowan DD, Dymock JJ 1990. The role of Acremonium lolii mycotoxins in insect resistance of perennial ryegrass (Lolium perenne). Procceedings of the International Symposium on Acremonium/Grass Interactions. Baton Rouge. Pp. 44-48.

Popay AJ, Townsend RJ, Fletcher LR 2003. The effect of endophyte (Neotyphodium uncinatum) in meadow fescue on grass grub larvae. New Zealand Plant Protection 56: $123-128$.

Popay AJ, Jensen JG, Cooper BM 2005. The effect of non-toxic endophytes in tall fescue on two major insect pests. Proceedings of the New Zealand Grassland Association 67: 169-173.

Prestidge RA, Gallagher RT 1985. Lolitrem B - a stem weevil toxin isolated from Acremonium-infected ryegrass. Proceedings of the 38th New Zealand Weed and Pest Control Conference 38: 38-40.

Reidell WE, Kieckhefer RE, Petroski RJ, Powell RG 1991. Naturally occurring and synthetic loline alkaloid derivatives: insect feeding behavior modification and toxicity. Journal of Entomological Science 26: 122-129.

Schardl CL, Grossman RB, Nagabhyru P, Faulkner JR, Mallik UP 2007. Loline alkaloids: Currencies of mutualism. Phytochemistry 68: 980-996.

Schmidt D, Guy PL 1997. Effects of the presence of the endophyte Acremonium uncinatum and of an insecticide treatment on seed production of meadow fescue. Revue Suisse d'Agriculture 29: 97-99.

Wilkinson HH, Siegel MR, Blankenship JD, Mallory AC, Bush LP, Schardl CL 2000. Contribution of fungal loline alkaloids to protection from aphids in a grass-endophyte mutualism. Molecular Plant Microbe Interactions 13: 1027-1033.

Yates SG, Fenster JC, Bartelt RJ 1989. Assay of tall fescue seed extracts, fractions, and alkaloids using the large milkweed bug. Journal of Agricultural and Food Chemistry 37: 354-357. 